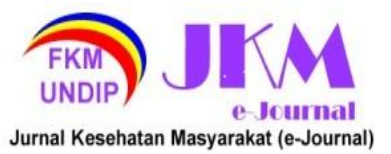

JURNAL KESEHATAN MASYARAKAT (e-Journal)

Volume 9, Nomor 6, November 2021

ISSN: 2715-5617 / e-ISSN: 2356-3346

http://ejournal3.undip.ac.id/index.php/jkm

\title{
ANALISIS PENINGKATAN STANDAR PELAYANAN MINIMAL PADA USIA PENDIDIKAN DASAR SELAMA PANDEMI COVID-19 DI PUSKESMAS ANDALAS KOTA PADANG
}

\author{
Yuni Afrianis $^{1^{*}}$, Chriswardani Suryawati ${ }^{2}$, Wulan Kusumastuti ${ }^{2}$ \\ ${ }^{1}$ Peminatan Admnistrasi Kebijakan Kesehatan Fakultas Kesehatan Masyarakat Universitas \\ Diponegoro Jl. Prof. H. Soedarto, S.H.,Tembalang, Semarang, Indonesia \\ 2Bagian Admnistrasi Kebijakan Kesehatan Fakultas Kesehatan Masyarakat Universitas Diponegoro \\ J. Prof. H. Soedarto, S.H.,Tembalang, Semarang, Indonesia \\ ${ }^{*}$ Corresponding author: yuniafrianis2029@gmail.com
}

\begin{abstract}
During the Covid-19 pandemic, the implementation of the MSS (Minimum Service Standards) program age of basic education was hampered. Andalas public health center is health center with the lowest achievement of basic education age MSS in Padang City in 2020 with an achievement of 0\%. This study aims to analyze the anticipation of the Andalas public health center in Padang City in increasing the coverage of MSS for basic education age in 2021. This study uses a qualitative method through indepth interviews with selected informants based on purposive sampling criteria. The aspects studied consist of input, process, and output variables. The results showed a lack of knowledge of officers related to Minister of Health regulations RI No. 4 of 2019, facilities and infrastructure are adequate, data collection in 2021 through nutritional status data sent by the school, July data collection was carried out via google form, services followed standard operating procedures, recording by schools, reporting sent to the Padang City Health Office, monev by the City Health Office and the Head of the Puskesmas. Andalas Health Center's efforts to pursue the 2021 target, if the pandemic ends, the puskesmas maximizes direct health checks, if the pandemic is not over, the puskesmas will conduct a health check through the google form. continue to run the program by complying with health protocols. The City Health Office is expected to conduct regular monitoring, build communication, cooperate with puskesmas, and strengthen sanctions if the MSS does not reach the target.
\end{abstract}

Keywords: Minimum Service Standards, age of basic education, Andalas Health Center

\section{PENDAHULUAN}

Berdasarkan undang-undang Nomor 36 Tahun 2009 menjelaskan kesehatan tiap orang berhak menerima pelayanan kesehatan yang bermutu, terjangkau dan aman. Pernyataan ini menjadi landasan kepercayaan bahwa kesehatan merupakan hal penting yang berhak didapatkan tiap orang dan menjadi kewajiban pemerintah untuk menjamin agar tiap warganya mampu dan mau untuk hidup sehat serta memanfaatkan pelayanan kesehatan yang bermutu. ${ }^{(1)}$

Pelayanan bermutu bisa tercapai jika mempunyai acuan serta standar yang dijadikan landasan untuk melakukan pelayanan. Pemerintah memberi dukungan upaya pelayanan bermutu dengan mengeluarkan Permenkes nomor 4 tahun 2019 mengenai standar pelayanan minial bidang kesehatan. Standar pelayanan minimal (SPM) bidang kesehatan adalah ketentuan mengenai mutu serta jenis pelayanan kesehatan dasar yang berhak didapatkan oleh warga secara minimal. Standar pelayanan minimal ialah hal minimal yang wajib dilakukan pemerintah daerah pada masyarakat, dengan capaian standar 100\% setiap tahunnya.(2) Didalam Konsep SPM yang telah berubah berawal dari kinerja program kementrian dan menjadi kinerja Pemerintah Daerah yang telah mempunyai pengaruh punishment serta reward.(3) Puskesmas sebagai unit pertama pada upaya kegiatan pencapaian target standar pelayanan minimal.(4)

Berdasarkan hasil studi pendahuluan di Dinas Kesehatan Kota Padang, pada tahun 2020 provinsi Sumatera Barat menempati peringkat ke-3 cakupan SPM bidang kesehatan dengan besaran persentase $26 \%$ di Indonesia, sedangkan Sumatera Barat menempati peringkat ke-2 cakupan SPM bidang kesehatan terendah di kepulauan Sumatera. Penurunan cakupan SPM bidang kesehatan dialami oleh seluruh kabupaten/kota, salah satunya Kota Padang. Kota Padang berada di peringkat ke-2 cakupan SPM terendah di Sumatera Barat. Penurunan yang terjadi di Kota Padang per20 Desember tahun 2020 mencapai hingga $51,9 \%$. Angka ini sangat jauh dibandingkan dengan tahun sebelumnya dengan capaian SPM bidang kesehatan yaitu $97,8 \%$. Selain itu, didapatkan informasi jumlah Puskesmas yang 


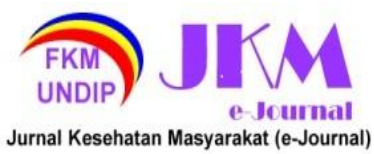

berada di wilayah kota Padang yaitu 23 Puskesmas. Pada tahun 2020 salah satu Puskesmas dengan capaian SPM bidang kesehatan terendah yaitu Puskesmas Andalas, dengan capaian SPM 50\%. Menurut hasil studi pendahuluan yang dilaksanakan di Puskesmas Andalas Kota Padang, didapatkan informasi sebelum adanya pandemi Covid-19 Puskesmas Andalas merupakan puskesmas yang paling mendekati pencapaian target SPM bidang kesehatan yaitu 95,5\%. Akan tetapi, pada saat pandemi capaian SPM bidang Kesehatan di Puskesmas Andalas menurun secara signifikan.

Capaian SPM Puskesmas Andalas tahun 2020 yaitu pelayanan kesehatan ibu hamil dengan pencapaian $78,89 \%$, pelayanan pada ibu bersalin dengan pencapian $100 \%$, pelayanan kesehatan pada bayi baru lahir dengan pencapaian $70,35 \%$, pelayanan kesehatan balita dengan pencapaian $67,11 \%$, pelayanan kesehatan usia pendidikan dasar dengan pencapaian $0 \%$, pelayanan kesehatan usia produktif dengan pencapaian $23 \%$, pelayanan kesehatan lansia dengan pencapaian $53,01 \%$, pelayanan pada penderita hipertensi denagan capaian $8,11 \%$, pelayanan pada DM dengan pencapaian 30,67\%, pelayanan kesehatan ODGJ dengan pencapaian $61,54 \%$, pelayanan kesehatan orang terduga tuberculosis dengan pencapaian $69,51 \%$, dan pelayanan kesehatan pada orang terduga HIV dengan capaian $41,10 \%$.(5)

Berdasarkan uraian diatas terdapat masalah yaitu pada masa pandemi Covid-19 pencapaian SPM bidang kesehatan usia pendidikan dasar di puskesmas Andalas $0 \%$. Hal ini memperlihatkan pelayanan kesehatan pada usia pendidikan dasar belum dilakukan. Menurut Indawati (2021), pelayanan pada usia pendidikan dasar merupakan suatu prosedur pemeriksaan kesehatan yang dilakukan untuk memilah (skrining) anak yang sehat dan tidak sehat, serta dapat dimanfaatkan untuk pemetaan kesehatan peserta didik. Kegiatan ini dilaksanakan untuk memenuhi persyaratan SPM, dan menurut Sriawan (2018), tujuan pelayanan kesehatan di sekolah adalah untuk meningkatkan kemampuan dan keterampilan melakukan tindakan hidup sehat, dalam rangka membentuk perilaku hidup sehat, sedangkan menurut penelitian Astutik (2017), apabila pelayanan kesehatan pada usia pendidikan dasar tidak dilakukan maka akan mengakibatkan anak menjadi obesitas, stunting, marasmus, anemia dan penyakit lainnya, karena anak terus tumbuh dari tahun ke tahun, terjadi perubahan antropometri dan komposisi tubuh secara drastis. Maka dibutuhkan suatu pemantauan status gizi agar mengetahui setiap perubahan yang terjadi.

Pada Permenkes No.4 Tahun 2019 tentang SPM bidang kesehatan menjelaskan semua indikator SPM termasuk SPM pada usia Pendidikan dasar harus mencapai target $100 \%$. Tedapat 7 standar pelayanan dalam mekanisme pelayanan kesehatan pada usia Pendidikan dasar yaitu 1) Penilaian tanda vital, 2) Penilaian status gizi, 3) Penilaian ketajaman indera, 4) Penilaian kesehatan gigi dan mulut, 5) Pemberian tablet tambah darah, 6) Pemberian obat cacing, 7) Pemberian imunisasi campak dan diptheria tetanus. Tujuh standar pada pelayanan usia pendidikan dasar dilaksanakan minimal satu kali dalam setahun. (8) Selama pandemi Covid-19 pelayanan kesehatan usia pendidikan dasar yang bisa dilakukan yaitu penilaian status gizi, pemberian tamblet tambah darah, pemberian obat cacing, dan pemberian imunisasi. Sedangakan untuk penilaian tanda vital, penilaian ketajaman indera, dan penilaian kesehatan gigi dan mulut tidak bisa dilakukan karena pembelajaran dilakukan secara daring.

Pada penelitian ini peneliti meneliti priode 2021 karena dilihat pada priode 2020 pencapaian SPM pada usia pendidikan dasar masih $0 \%$ dan peneliti tertarik untuk mengetahui apa saja antisipasi yang dilakukan oleh Puskesmas Andalas Kota Padang dalam meningkatkan cakupan SPM bidang kesehatan pada usia pendidikan dasar tahun 2021. Sehingga peneliti akan melakukan penelitian mengenai analisis anatisipasi Puskesmas Andalas Kota Padang dalam meningkatkan standar pelayanan minimal bidang kesehatan pada usia pendidikan dasar tahun 2021, melalui variabel-variabel dalam teori pendekatan sisitem, yaitu input, proses, dan output. Pada penelitian sebelumnya teori ini digunakan untuk meneliti mengenai analisis Pencapaian Standar Pelayanan Minimal Bidang Kesehatan di Puskesmas Pauh Kota Padang.

Tujuan penelitian ini adalah menganalisis bagaimana antisipasi Puskesmas Andalas Kota Padang dalam meningkatkan cakupan SPM pada usia Pendidikan dasar tahun 2021.

\section{METODE PENELITIAN}

Penelitian dilaksanakan Maret sampai April 2021 di Puskesmas Andalas Kota Padang. Penelitian ini sudah lulus kaji etik nomor 100/EA/KEPK-FKM/2021. Penelitian ini menggunakan metode kualitatif dengan 


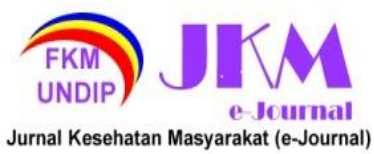

pendekatan sistem seperti wawancara mendalam (indepth interview) dengan informan utama dan informan triangulasi. Pemilihan subjek penelitian berdasarkan purposive sampling.

Informan utama terdiri dari 4 orang yaitu Penanggung jawab program SPM pada usia pendidikan dasar di Puskesmas Andalas (IU1), Pelaksana program SPM pada usia pendidikan dasar di Puskesmas Andalas (IU2, IU3) dan Kepala Puskesmas Andalas (IU4).

Informan triangulasi sebagi cross check dan validasi data berjumlah 6 orang, yaitu guru pendidikan jasmani olahraga dan kesehatan SD, SMP, dan SMA yang menjadi wilayah kerja Puskesmas Andalas Kota Padang (IT1, IT2, IT3, IT4, IT5, IT6)

Aspek yang diteliti terdiri dari variabel input meliputi kebijakan, tenaga, dana, sarana dan prasarana, variabel proses meliputi, pendataan, pelatihan, pelayanan, pencatatan dan pelaporan, monitoring dan evaluasi dan variabel output yaitu upaya yang dilakukan Puskesmas Andalas dalam meningkatkan cakupan SPM bidang kesehatan pada usia pendidikan dasar tahun 2021, selain itu analisis data yang digunakan terdiri dari pengumpulan data, kondensasi data, penyajian data, dan penarikan kesimpulan.

\section{HASIL DAN PEMBAHASAN}

1. Analisis Variabel Input Antisipasi Puskesmas Andalas Dalam Meningkatkan SPM Bidang Kesehatan Pada Usia Pendidikan Dasar

\section{a. Kebijakan}

Dari hasil penelitian yang dilakukan peneliti diketahui bahwa kebijakan pencapaian SPM bidang kesehatan secara umum berdasarkan peraturan kementrian kesehatan nomor 4 tahun 2019. Kebijakan tentang SPM sudah disosialisasikan kepada petugas Puskesmas Andalas, tetapi masih ada staff yang belum memahami mengenai isi Permenkes tersebut karena kepala puskesmas hanya menyampaikan program-program yang masuk SPM serta target yang harus dicapai oleh puskesmas. Sedangkan untuk indikator masing-masing SPM standar pencapaiannya tidak dijelaskan secara mendetail. Pada SPM usia pendidikan dasar point yang belum dipahami oleh petugas puskesmas yaitu indikator yang harus dilaksanakan setiap tahun. Petugas hanya memahami jika 6 indikator sudah dilaksanakan maka 1 indikator lain tidak perlu dilaksanakan seperti indikator penilaian ketajaman indera, karena menurut mereka penilaian ketajaman indera tidak perlu dilakukan pada anak usia sekolah dasar karena banyak penglihatan mereka yang masih normal. Penelitian ini sejalan dengan penelitian Purnama (2015) bahwa kebijakan tentang SPM bidang kesehatan sudah disosialisasikan kepada seluruh tenaga di Puskesmas Ciputat Timur. ${ }^{(9)}$

Proses sosialisasi mengenai kebijakan SPM bidang kesehatan di Puskesmas Andalas dilaksanakan secara berjenjang mulai dari Dinas Kesehatan Kota Padang mensosialisasikan kepada kepala puskesmas, lalu kepala puskesmas mensosialisasikan kepada petugas di puskesmas. Sosialsisasi dilakukan pada saat pertemuan bulanan Puskesmas Andalas. Selain itu, target 100\% yang ditetapkan dalam Permenkes No. 4 Tahun 2019 sulit dicapai pada masa pandemi Covid19 terutama pada pelayanan kesehatan usia pendidikan dasar dengan capaian $0 \%$.

\section{b. Tenaga}

Tenaga adalah aspek yang sangat penting untuk tercapainya keberhasilan dalam pelaksanaan pembangunan, meningkatkan pelayanan kepada masyarakat, serta penyelenggaraan pemerintahan. ${ }^{(10)}$ Tenaga pelaksana untuk program SPM pada usia pendidikan dasar di Puskesmas Andalas berjumlah 4 orang berlatar belakang pendidikan, D3-Kebidanan, S1-Keperawatan dan D2-Gizi. Jumlah tenaga pada SPM usia pendidikan dasar pada kondisi normal masih kurang karena masih ada tenaga yang memiliki beban kerja ganda dan memiliki wilayah kerja luas, akan tetapi pada masa pandemi sudah mencukupi karena untuk penilaian status gizi dilakukan melalui google form, dan untuk kegiatan pemberian obat cacing, obat TTD dibantu oleh guru kelas serta pada saat imunisasi adanya pengaturan jumlah siswa. Puskesmas Andalas memiliki sasaran 80 sekolah dengan jumlah siswa 6.394 orang. Hasil penelitian ini tidak sejalan dengan penelitian Maulana (2019) bahwa sumberdaya manusia di Puskesmas Mayong masih belum mencukupi dan menjadi hambatan dalam pencapaian indikator SPM di Puskesmas Mayong. ${ }^{(10)}$

\section{c. Dana}

Dana pelayanan kesehatan SPM usia pendidikan dasar di Puskesmas Andalas bersumber dari dana BOK. Ketersediaan dana pelayanan kesehatan SPM usia pendidikan dasar pada kondisi normal belum mencukupi, akan tetapi selama pandemi dana di Puskesmas Andalas sudah mencukupi karena pada pandemi kegiatan tidak sepenuhnya bisa berjalan, Alokasi dana digunakan untuk biaya 


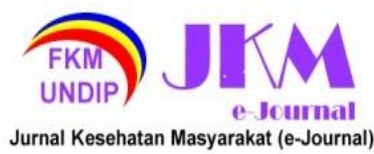

obat-obatan, pengadaan buku catatan, pengadaan formulir rekapitulasi di sekolah dan pengadaan formulir rujukan. Menurut Rosita (2021) dana adalah faktor utama yang berperan untuk mewujudkan pelayanan. Apabila dana tidak mencukupi, maka banyak program yang seharusnya dilaksanakan secara maksimal menjadi tidak maksimal dilakukan. ${ }^{(11)}$

Pencairan dana dilakukan setiap tahun. Hasil penelitian sejalan dengan penelitian Jaya (2015) bahwa jumlah dana di Puskesmas Ciputat Timur sudah mencukupi untuk pelaksanaan pelayanan kesehatan. Sumber dana pelaksanaan pelayanan kesehatan di Puskesmas Ciputat Timur berasal dari dana BOK dan JKN. ${ }^{(9)}$

Dana BOK (Bantuan Operasional Kesehatan) adalah bantuan pemerintahan pusat ke pemerintah daerah yang ditransferkan secara langsung ke dalam APBD (Anggaran dan Pendapatan Belanja Daerah) pada tingkat kabupaten/kota melalui mekanisme DAK (Dana Alokasi Khusus) untuk menunjang puskesmas dalam pencapaian program kesehatan prioritas nasional. Dana BOK diarahkan untuk meningkatkan kinerja puskesmas dalam upaya kesehatan promotif dan preventif dalam mendukung pelayanan kesehatan di luar gedung dengan didukung manajemen puskesmas yang baik. ${ }^{(12)}$

\section{d. Sarana dan Prasarana}

Hasil penelitian menyatakan sarana dan prasarana pada SPM usia pendidikan dasar terdiri dari timbangan dan mikrotoa yang digunakan sebagai penilaian status gizi. Termometer, tensimeter digunakan sebagai penilaian tanda vital. Ishihara atau gambar lingkaran yang terdiri dari banyak bintik dengan warna dan bentuk yang berbeda satu sama lain digunakan untuk penilaian ketajaman indera (tes buta warna). Pada Puskesmas Andalas saat kondisi normal ketersedian dan kondisi sarana dan prasarana belum mencukupi, seperti timbangan dan mikrotoa masih terbatas, serta kondisi timbangan juga tidak bagus kadang ada yang rusak, akan tetapi selama pandemi ketersediaan dan kondisi sarana dan prasarana dalam mendukung pelayanan kesehatan pada SPM usia pendidikan dasar sudah mencukupi, karena pada masa pandemi untuk penilaian satus gizi menggunakan google form, sedangkan untuk peneilaian tanda vital dan penilaian ketajaman indera selama pandemi tidak dilakukan karena pembelajaran dilakukan secara online.

Hasil penelitian ini tidak sejalan dengan penelitian Elsa (2018) bahwa alat medis dan non medis yang tersedia di Puskesmas Pauh belum memenuhi kebutuhan dan masih perlu penambahan dalam rangka pencapaian indikator SPM bidang kesehatan.(13)

2. Analisis Variabel Proses Antisipasi Puskesmas Andalas dalam meningkatkan SPM Bidang Kesehatan Pada Usia Pendidikan Dasar

\section{a. Pendataan}

Menurut Wendhie (2013) data adalah suatu kejadian dan fakta yang terdokumentasikan dengan memiliki kodifikasi terstruktur untuk beberapa entitas. ${ }^{(14)}$ Berdasarkan hasil penelitian diketahui bahwa selama pandemi Covid-19 data yang diperlukan pada SPM usia pendidikan dasar yaitu terdiri dari nama sekolah, nama, alamat, umur, jenis kelamin, kelas, tinggi dan berat badan. Data ini digunakan untuk penilaian status gizi.

Pada tahun 2021 petugas tidak langsung turun kelapangan untuk mendata, akan tetapi data untuk penilaian status gizi dikirim oleh pihak sekolah ke puskesmas. Pada bulan Juli 2021 pendataan akan dilaksanakan melalui google form, yang mengirimkan kuesioner via google form yaitu guru kelas ke siswa kemudian diisi oleh siswa, pada siswa SD guru kelas mengirimkan kuesioner via google form kepada orangtua kemudian orangtua membantu mengisi kuesioner tersebut.

Data yang tersedia pada saat masa pandemi covid-19 yaitu data status gizi, data pemberian tablet tambah darah, data pemberian obat cacing, data pemberian imunisasi campak dan diptheria tetanus, sedangkan untuk data indikator lain seperti data penilaian kesehatan gigi dan mulut, data penilaian ketajaman indera, dan data penilaian tanda vital tidak ada. Hal ini berpengaruh kepada capaian SPM pada usia pendidikan dasar. Dari tujuh indikator pada SPM usia pendidikan dasar yang bisa dilaksanakan selama pandemi Covid-19 yaitu penilaian status gizi, pemberian tamblet tambah darah, pemberian obat cacing, dan pemberian imunisasi. Sedangakan untuk penilaian tanda vital, penilaian ketajaman indera, dan penilaian kesehatan gigi dan mulut tidak bisa dilakukan karena pembelajaran dilakukan secara daring.

\section{b. Pelatihan}

Staff yang melakukan pelayanan kesehatan di Puskesmas Andalas sudah mendapatkan pelatihan dari DKK Padang yang bertujuan untuk meningkatkan kompetensi petugas seperti, pelatihan komunikasi pelayanan kesehatan, pelatihan asuhan persalinan normal (APN), dan pelatihan mengenai protokol kesehatan. Hasil penelitian ini sejalan dengan Ridwan (2015) pelatihan guna meningkatkan 


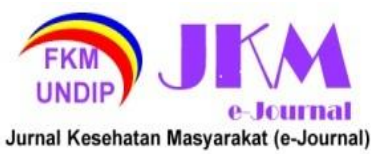

kompetensi tenaga di puskesmas Tuminting sudah dilaksanakan. ${ }^{(15)}$

Pelatihan dilakukan secara rutin tiap tahun dan diselenggaran oleh pihak Dinas Kesehatan Kota. Teknis pelatihan pada masa pandemi ada perbedaan yaitu pelatihan yang diberikan oleh DKK kepada puskesmas dilakukan via zoom. Pada tahun ini Puskesmas Andalas mengadakan pelatihan kepada kepala sekolah mengenai pengenalan google form, pelatihan ini diadakan di hotel Amaris Padang dengan tujuan agar pihak sekolah memahami skrining kesehatan via google form. Data yang harus ada pada kuesioner google form yaitu nama sekolah, nama, umur, alamat, jenis kelamin, kelas, tinggi badan, berat badan, riwayat kesehatan (memiliki masalah kesehatan, alergi makanan tertentu, alergi obat tertentu, saat ini minum obat, pernah dirawat dirumah sakit, pernah mengalami penyakit anemia, asma, batuk lama berulang, campak, DM, hepatitis, penyakit jantung, TBC, dan sakit kepala berulang).

\section{c. Pelayanan}

Hasil penelitian menyatakan pelayanan yang dilaksanakan pada SPM usia pendidikan dasar mengikuti kebijakan atau SOP yang ditetapkan oleh pimpinan Puskesmas Andalas. Hasil penelitian ini sejalan dengan penelitian Andriani (2014) bahwa petunjuk operasional adalah kebijakan yang dikeluarkan oleh kepala puskesmas serta digunakan untuk pedoman pelaksanaan kegiatan pelayanaan di Puskesmas Silungkang.(16)

Pada masa pandemi Covid-19 ada sedikit perubahan SOP yaitu, biasanya skrining dilakukan langsung ke sekolah, selama pandemi Covid-19 skrining kesehatan dilakukan dengan cara pengisian kuesioner via google form. Selain itu pemberian obat TTD, Cacing diberikan melalui janji temu dengan guru, sedangkan Imunisasi dilakukan dengan mengatur jadwal dan jumlah peserta didik. SOP yang dibuat mangacu pada Peraturan Kementrian Kesehatan Nomor 4 Tahun 2019 tentang SPM bidang kesehatan.

\section{d. Pencatatan dan Pelaporan}

Pencatatan dan pelaporan pada saat pandemi Covid-19, pencacatan pada SPM pada usia Pendidikan dasar tidak dilakukan langsung oleh Puskesmas Andalas, akan tetapi dibantu oleh pihak sekolah setelah itu pihak sekolah mengirimkan laporan ke puskesmas berkaitan dengan penilaian status gizi yang terdiri dari nama sekolah, alamat, nama, jenis kelamin, umur, kelas, tinggi dan berat badan. Kemudian setelah itu puskesmas menganalisis datanya dan apabila banyak permasalahan di suatu sekolah pihak sekolah melakukan pembinaan sekolah. Pelaporan dilakukan setiap bulan. Penanggung jawab program merekap hasil laporan dari guru lalu menyusunnya menjadi laporan bulanan program.

Kendala yang diindentifikasi dari proses pencatatan dan pelaporan adalah keterlambatan pengiriman laporan oleh pihak jejaring sekolah sehingga laporan Puskesmas Andalas terlambat dikirim ke Dinas Kesehatan Kota Padang. Hal ini sejalan dengan penelitian Elsa (2018) bahwa pelaporan di Puskesmas Pauh terkadang mengalami keterlambatan pengumpulan dari setiap pemegang program, laporan yang dihasilkan tidak akurat serta arsip laporan yang tidak lengkap.(13)

\section{e. Monitoring dan Evaluasi}

Hasil penelitian menyatakan telah dilaksanakan monitoring dan evaluasi terhadap SPM pada usia Pendidikan dasar di Puskesmas Andalas dilakukan oleh kepala puskesmas dan DKK Padang. Monitoring dan evaluasi dari pihak puskesmas dilakukan saat lokakarya mini bulanan dan lokakarya mini triwulan dilihat dari pencapaian dan kendala yang dihadapi dalam melakukan pelayanaan. Sedangkan dari pihak DKK melakukan pemantauan dengan cara Puskesmas Andalas mengirimkan laporan ke DKK. Bentuk monev dari pihak DKK apabila terjadi suatu permasalahan di sekolah maka DKK berkoordinasi dengan puskesmas kemudian puskesmas turun langsung untuk melakukan pembinaan sekolah. Hasil penetian ini sejalan dengan penelitian Elsa (2018) yang mengatakan bahwa pengawasan dan evaluasi yang dilakukan oleh DKK padang dan kepala puskesmas. ${ }^{(13)}$

Berdasarkan Peraturan Menteri Kesehatan Nomor 43 Tahun 2019 tentang puskesmas, pengawasan puskesmas terbagi 2 yaitu pengawasan eksternal dan internal. Pengawasan eksternal dilakukan oleh Dinas Kesehatan kabupaten/kota, intitusi lain dan masyarakat. Sedangkan pengawasan internal dilakukan oleh kepala puskesmas, penanggung jawab atau tim audit internal dan pelaksana program. ${ }^{(17)}$

3. Analisis Variabel Output Antisipasi
Puskesmas Andalas dalam meningkatkan
SPM Bidang Kesehatan Pada Usia
Pendidikan Dasar
Capaian SPM usia Pendidikan dasar selama pandemi di Puskesams Andalas belum mencapai target. Capaian SPM usia pendidikan dasar di Puskesmas Andalas tahun 2020 yaitu 


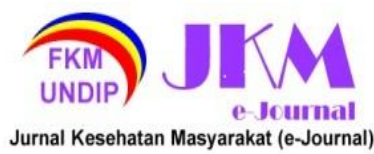

$0 \%$ hal ini disebabkan oleh program yang tidak bisa dijalankan karena sekolah diliburkan.

Berdasarkan hasil penelitian diketahui upaya yang dilakukan Puskesmas Andalas untuk kejar target tahun 2021 apabila pandemi sudah berakhir Puskesmas Andalas memaksimalkan skrining kesehatan secara langsung ke sekolah-sekolah sesuai wilayah kerja. Akan tetapi apabila pandemi belum berakhir maka Puskesmas Andalas melakukan penilaian satus gizi melalui google form. Selain itu melakukan pemberian obat TTD, cacing melalui janji temu dengan guru, imunisasi campak, imunisasi diptheria tetanus dilakukan dengan mengatur jadwal dan jumlah peserta didik. Sedangkan untuk kegiatan penilaian tanda vital, penilaian kesehatan gigi dan mulut, serta penilaian ketajaman indera belum bisa dilaksanakan karena pembelajaran dilakukan secara online.

Hal ini seperti diungkapkan oleh informan utama : "Apabila pandemi belum berakhir maka kita melakukan pendataan melalui goggle form dan melakukan pemberian obat TTD, Cacing melalui janji temu dengan guru, sedangkan Imunisasi dilakukan dengan mengatur jadwal dan jumlah peserta didik, dan apabila sudah berakhir kita memaksimalkan untuk turun lapangan ke sekolah-sekolah"(IU1)

Wilayah kerja Puskesmas Andalas terdiri dari 80 sekolah dengan jumlah siswa 6.394 orang. Adapun sanksi ketika cakupan SPM 0\% dari Dinas kesehatan Kota. Sanksi yang diberikan yaitu teguran untuk tetap melaksanakan program SPM pada usia Pendidikan dasar pada masa pandemi dengan mematuhi protokol kesehatan. Hasil penelitian menunjukkan selama tidak ada skrining kesehatan pada usia pendidikan dasar berdampak bagi kesehatan anak sekolah, seperti anak menjadi obesitas, stunting, marasmus, anemia dan penyakit lainnya. Penilaian ini sejalan dengan penelitian Ekawati (2020) apabila tidak dilakukan skrining kesehatan akan menyebabkan anak menjadi obesitas, stunting, marasmus dan anemia. ${ }^{(18)}$

\section{KESIMPULAN}

Capaian SPM pada usia Pendidikan dasar di Puskesmas Andalas pada tahun 2020 yaitu $0 \%$. Upaya yang dilakukan Puskesmas Andalas untuk kejar target tahun 2021 apabila pandemi sudah berakhir Puskesmas Andalas memaksimalkan skrining kesehatan secara langsung ke sekolah-sekolah sesuai wilayah kerja Puskesmas Andalas, akan tetapi apabila pandemi belum berakhir maka Puskesmas Andalas melakukan skrining kesehatan malalui google form, pemberian obat TTD, cacing diberikan melalui janji temu dengan guru, imunisasi dilakukan dengan mengatur jadwal dan jumlah peserta didik. Sedangkan untuk kegiatan penilaian tanda vital, penilaian kesehatan gigi dan mulut, serta penilaian ketajaman indera belum bisa dilaksanakan karena pembelajaran dilakukan secara online. Wilayah kerja Puskesmas Andalas terdiri dari 80 sekolah dengan jumlah siswa 6.394 orang. Adapun sanksi yang diberikan ketika cakupan SPM 0\% dari pihak DKK yaitu teguran untuk tetap melaksanakan program SPM pada usia pendidikan dasar pada masa pandemi dengan mematuhi protokol kesehatan, dan selama tidak ada skrining kesehatan pada usia pendidikan dasar berdampak bagi kesehatan anak sekolah, seperti anak menjadi obesitas, stunting, marasmus, anemia dan penyakit lainnya.

Dari hasil penelitian dapat diperoleh rekomendasi yaitu puskesmas tetap melakukan kegiatan pada SPM usia pendidikan dasar sesuai dengan protokol kesehatan, meningkatkan koordinasi dan komunikasi dengan pihak sekolah agar kegiatan berjalan sesuai dengan tujuan, serta rutin melaksanakan monitoring dan evaluasi untuk melihat ketercapaian program.

\section{UCAPAN TERIMAKASIH}

Ucapan terimakasih penulis sampaikan kepada Dinas Kesehatan Kota Padang yang telah mengizinkan kegiatan penelitian di Puskesmas Andalas Kota Padang. Para Penanggung jawab Standar Pelayanan Minimal pada usia pendidikan dasar yang telah memfasilitasi dan membantu dalam pengambilan data dilapangan. Serta guru olahraga tingakat SD, SMP, dan SMA yang turut mendukung kegiatan penelitian ini hingga selesai.

\section{DAFTAR PUSTAKA}

1. Kementrian Kesehatan Republik Indonesia. Undang-Undang Republik Indonesia Nomor 36 Tahun 2009 Tentang Kesehatan. Financ Innov [Internet]. 2009;2(1):1-18. Available from:

https://doi.org/10.1016/j.worlddev.2019.104 755

2. Kementrian Kesehatan Republik Indonesia. Kementrian Kesehatan Republik Indonesia. Peraturan Menteri Kesehatan Republik Indonesia Nomor 4 Tahun 2019 Tentang Standar Teknis Pemenuhan Mutu Pelayanan Dasar Pada Standar Pelayanan Minimal Bidang Kesehatan. 2019;15-6. 


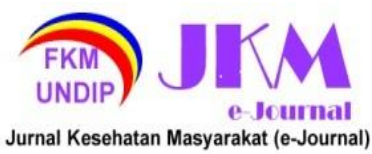

Available

from:

http://www.ghbook.ir/index.php?name=???

?? ? ????? ??? ????\&option=com_dbook\&t

ask=readonline $\& b o o k \_i d=13650 \&$ page $=73$

\&chkhashk=ED9C9491B4\&ltemid=218\&lan

$\mathrm{g}=\mathrm{fa} \& \mathrm{tmpl}=\mathrm{component}$

3. Dinas Kesehatan Provinsi Jawa Tengah. Pencapaian SPM Bidang Kesehatan Kabupaten / Kota Di Provinsi Jawa Tengah Tahun 2017. SPM Bid Kesehat. 2018;3511351(24).

4. Astutik. Standar Pelayanan Medis Nasional sebagai Bentuk Pembatasan Otonomi Profesi Medis National Medical Service Standard as Autonomy Limitation of. Standar Pelayanan Medis Nas sebagai Bentuk Pembatasan Oton Profesi Medis [Internet]. 2017;1(2):252-77. Available from: http://ojs.uho.ac.id/index.php/holrev/

5. Puskesmas Andalas. lokmin dkk. 2021.

6. Indawati L, Adijaya N, Dewi DR, Ilhami BF. Rekam Kesehatan Personal Pada Anak Usia Sekolah Sebagai Kunci Sukses Pemberdayaan Kesehatan Siswa. Educivilia J Pengabdi pada Masy. 2021;2(1):73.

7. Sriawan. Siswa Sekolah Dasar Sehat. Bhs dan Seni. 2018;31(2):172-97.

8. Puskesmas Andalas. Pedoman Pelayanan Kesehatan Anak Usia Sekolah di Puskesmas Andalas Di Masa Pandemi Covid-19. Kota Padang; 2020. 1-30 p.

9. Purnama WJ. Analisis Pelaksanaan Program Antenatal Care di Puskersmas Ciputat Timur Tahun 2015. Vol. 151, Nature Structural and Molecular Biology. 2015. 10$17 \mathrm{p}$.

10.Maula IN. Evaluasi Pelaksanaan Standar Pelayanan Minimal ( SPM ) Pada Penderita Hipertensi di UPTD Puskesmas Mayong I Kabupaten Jepara Tahun 2018. J Kesehat Masy. 2019;

11.Rosita R, Simamora TM. Penyelenggaraan Pelayanan Kesehatan Ibu dan Anak di Puskesmas Terpencil dan Sangat Terpencil di Masa Pandemi Covid-19. J Kaji dan Pengemb Kesehat Masy [Internet]. 2021;1(2):225-38. Available from: https://jurnal.umj.ac.id/index.php/ANNUR/article/view/8698

12. Inti M. Materi inti 5 pemanfaatan jkn dan bok di puskesmas. 2016;(28).

13.Riangga Astari Elsa. Analisis Pencapaian Standar Pelayanan Minimal Bidang Kesehatan di Puskesmas Pauh Kota Padang Tahun 2018 [Internet]. www.semanticscholar.org. 2018 [cited 2021 Feb 11]. Available from: https://www.semanticscholar.org/paper/AN
LESEHATAN MASYARAKAT (e-Journal)

Volume 9, Nomor 6, November 2021

ISSN: 2715-5617 / e-ISSN: 2356-3346

http://ejournal3.undip.ac.id/index.php/jkm

ALISIS-PENCAPAIAN-STANDAR-

PELAYANAN-MINIMAL-DI-E

14. Informasi PD dan. Pentingnya Data dan Informasi [Internet].

http://lpmpjogja.kemdikbud.go.id/pentingny a-data-dan-informasi/. 2013. Available from: http://lpmpjogja.kemdikbud.go.id/pentingny a-data-dan-informasi/

15.Ridwan L. Analisis Implementasi Standar Pelayanan Minimal (SPM) Dilihat Dari Pelayanan Kesehatan Dasar di Puskesmas Tuminting Kota Manado. J Manaj Kesehat Indones. 2015;7(1):1-8.

16.Andriani, Edison, Gracediani L. Implementasi pelayanan ibu hamil (K4) oleh bidan berdasarkan SPM di Puskemas Silungkang. J Kesehat Masy. 2014;8(1):2733.

17.Peraturan Menteri Kesehatan RI No 43 tahun 2019. Peraturan Menteri Kesehatan RI No 43 tahun 2019 tentang Puskesmas. Peratur Menteri Kesehat RI No 43 tahun 2019 tentang Puskesmas. 2019; Nomor 65(879):2004-6.

18. Fadliyana Ekawaty dkk. Skrining Obesitas Dan Edukasi Dampak Obesitas Pada Anak Di Sdn 49/lv Kota Jambi. Medic. 2020;3(2):91-4. 